his helpful comments in the preparation of this paper.

\section{References}

JACKSON, R. (1983) Mental retardation and criminal justice: some issues and problems. British Journal of Mental Subnormality, 29, 7-12.

Mayor, J., Bhate, M., FirTh, H., Graham, A., Knox, P. \& TYRER, S. (1990) Facilities for mentally impaired patients: three years of experience of a semi-secure unit. Psychiatric Bulletin, 14, 333-335.
PARKER, E. (1974) Survey of Incapacity associated with Mental Handicap at Rampton and Moss Side Special Hospitals. Special Hospitals Research Unit Publication 11, London.

ROBERTSON, G. (1981) The extent and pattern of crime amongst mentally handicapped offenders. Journal of the British Institute of Mental Handicap, 9, 100-103.

Royal College of Psychiatrists (1980) Secure facilities for psychiatric patients-a comprehensive policy. London: Royal College of Psychiatrists.

TURK, J. (1989) Forensic aspects of mental handicap. British Journal of Psychiatry, 155, 591-594.

\title{
Psychiatric audit
}

\author{
Paul Hatton, Senior Registrar in Public Health Medicine, District Headquarters \\ Offices, Department of Public Health Medicine, Leeds Western Health Authority, \\ Leeds General Infirmary, Great George Street, Leeds LS1 3EX; and EDWARD B. \\ Renvolze, Senior Registrar in Public Health Medicine, Leeds Western Health \\ Authority, and formerly Consultant Psychiatrist, York Health Authority
}

Medical audit has been defined "as the systematic, critical analysis of the quality of medical care, including the procedures used for diagnosis and treatment, the use of resources, and the resulting outcome and quality of life for the patient" (Department of Health, 1989).

The term "clinical audit" (Royal College of Psychiatrists, 1989) is preferable in psychiatry as it indicates that audit activities need to involve the work of all staff delivering health care to psychiatric patients.

Audit in psychiatry differs in some respects from audit in other clinical specialties. For example, it cannot be confined to in-patient activities as a considerable amount of psychiatric care is given in the community. Also, good clinical outcomes may be more difficult to define, and indeed psychiatric outcomes may be strongly influenced by family and socioeconomic factors outside the influence of the health service.

\section{Why undertake audit?}

Audit is essentially a tool (Royal College of Physicians, 1989) for:

(a) assessing and improving the quality of patient care

(b) enhancing medical education by promoting discussion between colleagues about practice (c) identifying ways of improving the efficiency of clinical care.

Medical audit has as its cornerstone, peer review of professional standards of care, and it can only be effectively conducted in an atmosphere of mutual trust.

Audit can be regarded as a continuous cycle which involves: observing current practice; defining and setting standards; comparing current practice with these standards; implementing necessary changes to enable these standards to be achieved; and finally observing the new practice. The cycle must be completed if the audit process is to be properly undertaken, so that any beneficial results from the audit process lead to change in everyday clinical practice.

For successful audit an organisational framework is required which includes: the appointment of a chairman and secretary; agreed terms of reference; and the holding of regular audit meetings on dates agreed well in advance with those responsible for presenting their audit findings. As well as the actual audit meeting, time is obviously needed for any necessary data extraction from clinical records, the preparation of audit reports, and for the implementation of any recommendations for change that arise as a result of audit. The time required for the audit process must be regarded as a legitimate use of clinicians' time. 


\section{The initial audit topic}

It has been suggested that an audit activity is more likely to succeed if the activity to be audited is easily defined, occurs sufficiently frequently to allow rapid data collection, uses sufficient resources to be thought worth the investment of study, and is amenable to change. It is also prudent to pick a simple topic initially, to allow confidence and experience to be gained before tackling a more complicated audit area.

One simple example of audit might be a comparison of the contents of a random sample of in-patient hospital case-notes against an agreed framework of what a standard psychiatric clerking should contain. Another possible audit technique is that of criterionbased audit in which accepted features of good practice-e.g. the use of well-validated diagnostic criteria; the key points to be recorded in the mental state examination; evidence of agreed therapy being implemented; adequacy of case-notes; communication of essential information to the patient, carers and general practitioner; and arrangements for follow-up at discharge - are initially identified, and then compared with current local practice.

A further method of audit in psychiatry is to audit adverse patient occurrences-e.g. suicide, or deliberate self-harm among in-patients.

\section{A framework for audit in psychiatry}

Donabedian (1988) suggested that the quality of medical care can be examined under three headings.

Structure i.e. the attributes of the settings in which care occurs, such as the facilities available, the numbers of staff, etc.

Process i.e. what is actually carried out in giving and receiving care. Hospitalisation rates, lengths of stay, out-patient and day patient attendance rates, and ECT rates, fall into this category.

Outcome i.e. the effects of health care on the health status of patients. Outcome is the most difficult parameter to measure in medicine, and particularly so in psychiatry. The use of rating scales to measure the success of psychiatric intervention not only on psychological functioning, but also on social and economic functioning, may be required.

Another useful framework to consider for audit is that provided by Maxwell (1985), who has proposed six dimensions of quality against which psychiatric care could be assessed: access to services; relevance to need; effectiveness; equity; social acceptability; and efficiency and economy.

\section{Maintenance of audit}

The audit literature has described four phases of medical audit: the first "philosophical" phase, when there is discussion about whether doctors should undertake audit; the second "organisational" phase is concerned about who should be the lead person and what is needed to allow audit to take place; the third "practical" phase in which audit mechanisms and topics are agreed; and a fourth "invasive" phase when audit has become widely practised and audit ideas are disseminated throughout the medical profession. There does exist a possible fifth phase - that of audit "atrophy and necrosis". This occurs because of lack of interest in audit, and should be guarded against by ensuring that audit meetings are varied in their format, and that lively and stimulating debate occurs. Perhaps audit meetings themselves should be evaluated - an audit of audit!

\section{The benefits of psychiatric audit}

Many benefits can arise from audit: the use of collected clinical data in the audit process will lead to its validation and thus result in an overall improvement in the quality of health service data; audit meetings provide valuable learning opportunities for health care staff, and are a means of improving the training of doctors and fostering critical examination of currently accepted treatments; and clinical audit provides a forum in which a multidisciplinary group of health care professionals have a chance to comment on care issues in a trusting environment, and for themselves to recognise the need for change in their own practice, when indicated.

Finally, the most important benefit of psychiatric audit must surely be to identify and implement changes in clinical practice, which result in improvements to the quality of care received by patients.

\section{References}

DEPARTMENT OF HEALTH (1989) Medical Audit. Working for Patients. Working Paper Number 6. London: HMSO.

Donabedin, A. (1988) The quality of care. How can it be assessed? Journal of the American Medical Association, 260, 1743-1748.

MAXWELl, R. J. (1984) Quality assessment in health. British Medical Journal, 288, 1470-1472.

Royal College of Physicians of London (1989) Medical Audit. A First Report. What, Why and How?

Royal College of Pyschitrists (1989) Working Party of the Royal College of Psychiatrists: Preliminary report on medical audit. Psychiatric Bulletin, 13, 577-580. 